\title{
INTRODUCCIÓN
}

Thomas Schmitt (coord.) Universidad de La Rioja

\section{LA PEONZA}

Un filósofo solía ir a donde los niños jugaban. Veía a uno de ellos que tenía una peonza y se ponía al acecho. Apenas giraba la peonza, el filósofo la perseguía para cogerla. Que los niños gritaran e intentaran apartarle de su juguete, no le importunaba lo más mínimo. Si lograba coger la peonza mientras giraba, era feliz, pero sólo un instante, luego la arrojaba al suelo y se iba. Creía que el conocimiento de una pequeñez, por lo tanto también, por ejemplo, de una peonza girando, bastaba para alcanzar el conocimiento general. Por eso mismo no se ocupaba de los grandes problemas, lo que le parecía antieconómico; si realmente llegaba a conocer la pequeñez más diminuta, entonces lo habría conocido todo, así que se dedicaba exclusivamente a conocer la peonza. Y, siempre que comenzaban las preparaciones para hacerla girar, tenía la esperanza de que esa vez lo conseguiría, y cuando giraba corría tras ella poseído de la esperanza de una certeza, pero cuando sostenía ese burdo trozo de madera en la mano le daban náuseas, y el griterío de los niños, que antes no había escuchado y que ahora resonaba de repente en sus oídos, le impulsaba a huir, girando como una peonza bajo un látigo poco hábil'.

El esfuerzo y el empeño de conocer las cosas a fondo, tal y como lo describe metafóricamente Franz Kafka en esta parábola, es tan viejo como la humanidad misma. Entender las cosas auténticamente en su ente (recordemos el famoso grito literario de Juan Ramón "¡Intelijencia, dame el nombre exacto de las cosas!") o comprender un juego tan sencillo como el de la peonza que

1. http://elrincondelperromugre.blogspot.com.es/2010/12/franz-kafka-seleccion-de-textosbreves.html. 
gira -toda esta voluntad de conocer el fondo de las cosas, y en última instancia el mundo, es decir, a nosotros, es muy humana y está condicionada antropológicamente. Sin embargo, el despertar de tal sed de conocimiento queda frenado a menudo bruscamente, así parece, pues cada pregunta conlleva otra pregunta nueva en vez de concluir con certezas y respuestas definitivas. Un conocimiento auténtico y profundo sobre un asunto, sea este una simple peonza, el arte o la música, no parece posible, pues percibimos y entendemos siempre un solo aspecto: o la materia del objeto, la madera; esta música de Bach que suena ahora mismo. O el movimiento de la peonza donde la materialidad se ha ausentado o aquella música concreta que silba alguien en la calle. Todos estos momentos revelan solo los fenotipos de la música, por lo que la pregunta por la idea de la música se hace más que necesaria. Sin embargo, el duro proceso del conocimiento nos remonta siempre a ese burdo trozo de madera y, como vamos a ver en esta selección de textos, la música no es ninguna excepción.

La aparentemente sencilla pregunta "¿qué es la música?" se parece, en este sentido, a la idea del juego de peonza: a primera vista nos es familiar, conocido y una evidencia: todo el mundo sabe lo que es la música, la escuchamos, además, todos los días en casi todos los sitios. Pero al contemplar algo más o mejor "la música" uno se da cuenta de que el asunto no es tan fácil como parece. Una muestra de este problema que surge al querer definir la música la vemos en el simple hecho de que en los últimos 3000 años (empezando con los griegos) no haya salido ni una definición duradera y aceptada por todas las culturas. Más bien ha ocurrido lo contrario: cada época aporta su propia definición del quid musica sit; cada nuevo momento histórico desanda lo andado, comienza la búsqueda de nuevo, y así seguimos hasta ahora. Y, eso es lo más grave, a menudo los modelos de comprensión sobre la música no tienen nada en común, salvo quizá que se refieren a un fenómeno sonoro.

Citamos a continuación algunos conceptos de cómo se ha entendido la música en diferentes momentos históricos para darnos cuenta de que estas ideas tienen muy poco en común. Ya con los griegos comienza el problema de una clara e inequívoca definición de la música: era, y este es su primer significado, una téchnē como cualquier otra habilidad para producir algo. Pero como téchnē comprendía la melodía y el ritmo, la palabra y la danza. Aún más, Platón vincula la música directamente con la filosofía:

«¡Sócrates, haz música [musiké] y aplícate a ello!» Y yo, en mi vida pasada, creía que el sueño me exhortaba y animaba a lo que precisamente yo hacía, como los que animan a los corredores, y a mí también el sueño me animaba a eso que yo practicaba, hacer música, en la convicción de que la filosofía era la más alta música, y que yo la practicaba².

2. Platón, Fedón. Madrid, Gredos, 1988 (60e-61a), p. 33. 
Cuando Sócrates pronuncia estas frases un día antes de su muerte, en la cárcel y acusado de corrupción, se refiere a una música más bien abstracta y metafísica que, igual que la filosofía, fuera capaz de explicar racionalmente el mundo. Hacer música, en este sentido, es lo mismo que filosofar: ambos son sustancialmente lo mismo, son métodos para entender y explicar el mundo. En los siglos siguientes estos diferentes significados siguen siendo determinantes pero ponderan o más la parte práctica o más la filosófica-espiritual.

Obviamente, el cristianismo remodela su concepto de música en función de la iglesia, pero mantiene la parte práctica de la música. Es ars (la traducción latina de la téchnē griega) en el sentido de hacer cosas u objetos cotidianos, igual que el "arte de hacer mesas" o "el arte de construir casas". El aspecto estético queda subordinado a la funcionalidad de las cosas producidas; lo que prima es la finalidad conseguida con el arte. Por tanto, es comprensible que San Agustín viera la música como servicio de la iglesia, como útil costumbre para memorizar más fácilmente el texto del mensaje eclesiástico.

Pero cuando me acuerdo de las lágrimas que derramé con los cánticos de tu iglesia en los comienzos de mi conversión y de la conmoción que ahora siento -no con el canto, sino con las cosas que se cantan, al ser cantadas con voz clara y modulación adaptadísima- reconozco una vez más la gran utilidad de esta costumbre ${ }^{3}$.

Junto a esa función propedéutica de la música San Agustín define la música (en el tratado De musica el maestro se lo pregunta al alumno: defini ergo musicam) con su famosa y conocida frase: musica est scientia bene modulandi. De hecho que esta pregunta en última instancia no versa sobre la "música" sino sobre la "teoría de la música" (como diríamos hoy en día): la música es un arte (en el sentido griego del hacer algo) que mide el movimiento en todas las cosas (que en toda obra bien hecha, aun fuera de la música, hay que guardar medida) ${ }^{4}$; lo mide, además, correctamente porque cada movimiento debe estar ordenado numéricamente; y es, por último, una ciencia porque la teoría de la música, y su razonamiento del sonido, permite justificar el alma incorporal, que es la meta de toda la argumentación del Santo de Hipona.

La diferencia entre el cantor y el musicus marcó durante toda la Edad Media también la distancia entre el músico práctico y el teórico, este último, obviamente, más estimado que el primero. En el Renacimiento esta jerarquía cambia: el artista, que antes, en la Edad Media, solo hacía legible lo divino mediante sus creaciones, se convierte ahora en una persona más segura de sí misma, y no

3. San Agustín, Confesiones. Madrid, Alianza, 1990, libro X, 33, p. 296.

4. San Agustín, De musica. Madrid, Biblioteca de autores cristianos, 1988, p. 74 (Obras completas XXXIX). [...] quod in omnibus etiam praeter musicam factis modus servandus est. 
necesariamente sometida a la restricción religiosa. Las cosas ya no son exclusivamente cifras de lo divino sino que ya hablan por sí mismas. Esta nueva actitud se refleja también en la música, que ahora no se considera exclusivamente en función de Dios ni definida por un orden abstracto-métrico, sino simplemente, y como lo expresa Johannes Tinctoris en su diccionario de 1495, "el arte reglado que consta del canto y del tono" ${ }^{\prime \prime}$. Ahora se acepta incluso el oído como herramienta juzgadora de la música pues, según Tinctoris, una "consonancia es algo que suena agradable a los oídos" ${ }^{\prime \prime}$. O, como lo expresa algo más de cien años después Descartes al comienzo de la época moderna, la "finalidad de la música es deleitar y provocar en nosotros pasiones diversas" ${ }^{\prime 7}$. El modelo por excelencia para la música, un patrón que reunió tanto una estructura sintáctica como una expresividad, todo ordenado en el tiempo y basándose en armonía y melodía, fue el lenguaje, por lo que Johann Mattheson podía definir en 1739 sin problema la música como lenguaje. El problema surge, como ya he dicho más arriba, si juzgamos una música que se basa en otros parámetros. Cuando el inglés William Hamilton Bird edita en 1789 una antología con música de la antigua Indostán tiene precisamente este problema que explica en la introducción:

The Compiler of the following airs heartily regrets the great insipidity which must attend the frequent repetition of subject, and their want of variety; and he fears the variations will be poorly compensate. He has strictly adhered to the original composition, though it has cost him great pains to bring them into any form as to TIME, which the music of Hindostan is extremly deficient in. The airs of Cashimere and Rohlcund are most perfect and regular; but even those, in their being sung, need the grace of a Chanam, and the expression of a Dillsook, to render them pleasing. The greatest imperfection, however, in the music in every part of India, is the total want of accompanyments; a third, or fifth, are additions, the Compilor, during a residence of nineteen years in this country, and with the most favorable opportunities, has never heard; and neither composer or performs have had an idea exceeding an octave, though their modulations constantly require relief to the ear ${ }^{8}$.

Aquí tenemos todos los prejuicios juntos respecto a esta música: es insípida y deficiente, Ilena de repeticiones, no dispone de un compás fijo, no lleva un

5. Tinctoris, Johannes, Terminorum musicae diffinitorium. Treviso, 1495. Ed. por Peter Gülke, Kassel, Bärenreiter, 1983, p. 50. Musica est modulandi peritia, cantu sonoque consistens.

6. Ídem, p. 42. Concordantia est sonorum diversorum mixtura dulciter auribus conveniens, et haec aut perfecta aut imperfecta est.

7. Descartes, René, Compendio de música (1612). Madrid, Técnos, 1992, p. 55.

8. Bird, William Hamilton, The oriental miscellany being a collection of the most favourite airs of hindoostan. Calcutta, 1789) http://imslp.org/wiki/The_Oriental_Miscellany_(Bird,_ William_Hamilton). 
acompañamiento; no hay quintas ni octavas, y la melodía no excede a la octava. No es de extrañar, pues el "ideal" de la música europea se basaba siempre en la melodía y la armonía (con pequeñas ponderaciones entre los parámetros). Jean-Jacques Rousseau lo resume en su Diccionario de música (1775): "La música se divide actualmente de una forma más simple en melodía y armonía, puesto que la rítmica ya no significa nada para nosotros" ${ }^{\prime 9}$.

Este modelo de música, considerada, además, como dada por naturaleza, predomina hasta nuestro siglo en la música europea. Aunque en el siglo XIX filósofos de importancia reflexionaron frecuentemente y con ingeniosidad sobre la música, no hay dudas. Para Søren Kierkegaard el modelo musical sobre el cual construye gran parte de su filosofía es Mozart (sobre todo la ópera Don Juan); y Arthur Schopenhauer, que quiere ver en la música una representación inmediata de la voluntad, piensa en compositores como Haydn, Mozart, Beethoven y Rossini. Friedrich Nietzsche, a su vez, se orienta en Wagner y posteriormente en Bizet. Podríamos citar a otros filósofos (Heidegger, Bloch, Adorno, etc.) pero siempre es lo mismo: su filosofía remite siempre a la arraigada tradición musical europea que prima la categoría de la "obra", la "armonía" y la "melodía", tal y como ya las había definido Rousseau en el siglo XVIII.

Esta imposibilidad de definir de manera universal la música o de conseguir por lo menos un mínimo de consenso respecto a lo que es, tampoco se resuelve mediante una visión más bien global y general. Es decir, el acercamiento "desde fuera", o entender la música dentro de un sistema mayor, tampoco produce plena satisfacción. Un ejemplo conocido para esta concepción es sin ninguna duda el de Georg Wilhelm Friedrich Hegel, para el que la música pertenece a un largo proceso de desarrollo del espíritu que pasa por el arte, la religión y finalmente la filosofía. Su sistema de las artes se basa en la suposición de que la forma y el contenido permanecen inseparablemente juntos. Como consecuencia de esta presunción, el arte, como manifestación sensible de la idea ${ }^{10}$ tiene para Hegel dos caras: una parte más bien sensual-material, y otra parte de un contenido espiritual; es decir, el arte oscila entre lo sensual y lo espiritual. Según esta idea, que le sirve a Hegel como hilo conductor para todo su sistema, las artes se ordenan jerárquicamente en función de si destacan más lo

9. Rousseau, Jean-Jacques, Diccionario de música. Ed. por José L. de la Fuente Charfolé, Madrid, Akal, 2007, p. 283, artículo Música.

Jean-Philippe Rameau es similar en su definición: "La música es la ciencia del sonido [...] La música generalmente se divide en la armonía y la melodía, pero como vamos a mostrar a continuación, esta última [la melodía] forma parte de la primera. [LA Musique est la Science des Sons; On divise ordinairement la Musique en Harmonie et en Melodie, quoique celle-cy ne soit qu'une partie de l'autre [...]". Véase, Traité de I'harmonie, Paris, 1722. (http://conquest.imslp.info/files/ imglnks/usimg/b/b8/IMSLP81588-PMLP166232-Trait_.pdf).

10. Hegel, G.W.F., Ästhetk. Stuttgart, Reclam, 1989, p. 179. Hegel habla del sinnliches Scheinen der Idee. 
material o lo espiritual. El ideal en el arte, por tanto, se muestra en la plástica o la escultura (griega) donde existe un perfecto equilibrio entre el material sensual (por ejemplo el mármol) con un contenido altamente espiritual que revela exactamente esta idea de la figura. Las otras artes se juzgan en función de alejarse del ideal, o por su material o por lo espiritual: en la arquitectura predomina claramente lo material, más que en la pintura; y en la literatura prevalece la formación espiritual, en grado mayor incluso que en la música. Esta "desventaja" de la música respecto a la literatura, según Hegel, se debe al simple hecho de que ella tiene que usar sonidos reales para la composición. Y consecuentemente la literatura es el arte más espiritual debido a que todas las historias que cuenta ocurren solo en la esfera de lo espiritual, sin que haya ningún material sensual por medio. Todo este concepto lo interpreta Hegel a través de la historia, como si fuera un organismo que nace, crece y muere: el arte simbólica la asigna al tiempo arcaico, con un claro predominio de lo material sensual (visible en los pirámides); el esplendor del arte lo encontramos en la antigüedad clásica de los griegos, donde la escultura había conseguido finalmente su máxima perfección; el decline del arte se ve posteriormente en el "tiempo romántico" de la Edad Media donde prima lo espiritual: la música, por tanto, ya es en cierto modo una expresión de esta decadencia. De todas maneras, este desarrollo del arte lo ve Hegel también superado en algún momento, precisamente cuando la religión sustituya al arte, que a su vez estará contenido en la filosofía.

Esta facilidad de partir de un sistema filosófico que subordina todos los fenómenos del arte a una idea superior, formando una unidad de las artes, tiene su precio o su punto débil, pues (como sabemos hoy) tanto el material sensual puede expresar una espiritualidad (solo basta pensar en la pintura de Vasili Kandinsky donde los colores mismos ya están cargados de una alta espiritualidad) como al revés también: lo espiritual de la música nos afecta sensualmente; solo hay que pensar en un concierto (sea este de rock o de música clásica) y su afectación visible en la conocida "piel de gallina". Es decir, la relación entre el material sensual y su contenido espiritual es mucho más rica de lo que Hegel presuponía. Aún más, implícitamente parte de una "estética de la obra" que presupone una esencia o un ente en una obra musical (que en última instancia revela la "verdad"). La aparente ventaja de este procedimiento es que se puede ordenar y clasificar la historia de la música según un canon de la producción artístico-musical. Pero como ha mostrado la nueva musicología a partir de los años 80 del siglo XX, la obra como base y fundamento para una "historia de la música" o de las artes es dudosa y está obsoleta.

Otra posibilidad de entender la música a través de un sistema mayor (y de definirla de esta manera inconfundiblemente) la podemos encontrar en Gotthold Ephraim Lessing, en su Laocoonte o sobre los límites en la pintura y poesía (1766). Pese a que no habla de la música en concreto, encontramos, sin embargo, una teoría del "arte del tiempo". Lessing cuestiona en este ensayo la teoría (aceptada hasta entonces) de que la pintura sea una forma de poesía 
muda, y, al revés, la poesía una pintura que hable (tal y como lo había expresado Horacio con su ut pictura poesis). Su objeción ahora es que existe entre la pintura y la poesía (y la música, podríamos añadir) una diferencia fundamental: mientras que la poesía (y la música) trabaja con la consecución de hechos, la pintura es simultánea. Por tanto, las obras de las primeras son "arte del tiempo" por excelencia; las de la segunda, "arte del espacio"11.

De todas maneras, esta idea de Lessing que hoy en día se ha convertido en un tópico (es decir, que la música es algo que ocurre solo en el tiempo, como diferentes sucesos, uno tras el otro a lo largo de un hilo temporal) ya no se puede mantener como criterio. Basta pensar en los abundante ejemplos donde el espacio (real) es igual de importante para la música que su interpretación: el efecto de los cori spezzati que consigue Giovanni Gabrieli al dividir los coros aprovechando el espacio de la iglesia; o la colocación de la orquesta en un foso cubierto, como en el teatro de Bayreuth, para producir un aura musical de gran profundidad, con una sonoridad indirecta, más espacial que temporal. Podríamos mencionar otros ejemplos, también de la música contemporánea, pero la conclusión es la misma: la música no puede considerarse exclusivamente un arte temporal; por consiguiente no será un criterio universal.

Como hemos visto hasta ahora, ni los diferentes modelos históricos o paradigmas, ni el recurso a la suposición de un sistema mayor nos ofrecen una definición convincente. Convendría, por tanto, mirar algunos ejemplos concretos de la realidad musical para ver la posibilidad, o mejor dicho, la imposibilidad de una idea de lo que es la música. Sobre las sinfonías de los compositores clásicos, grosso modo, no cabe duda, pues, en nuestra concepción europea, su música es la encarnación de la música; aún más, sus obras han servido precisamente para definir la música. Sin embargo, metodológicamente este procedimiento no es correcto, pues para decir "qué es la madera" no basta enumerar solo ejemplos de objetos de madera (árbol, mesas, etc.). Pero, por cuestiones socio-políticas (que en este contexto no pueden analizarse) este paradigma de la música clásica dominaba y sigue dominando la cultura europea. Y la justificación de que esta música "clásica" se basa en la tonalidad (incluso para muchos teóricos algo "dado por naturaleza") fue tan insistente que las escasas críticas a esta supuesta "ley de tonalidad" (por ejemplo en los trabajos de Hermann von Helmholtz o también en los textos de Arnold Schönberg) apenas conseguían el eco o la resonancia que les correspondía.

Si el eje del modelo "música" fue la música clásica, entonces es obvio que tanto la música anterior (como la música modal) o la posterior, como la música dodecafónica, no son música, sino, más exactamente, artes a las que aún les fal-

11. Lessing, Gotthold Ephraim, Laocoonte. Ed. por Eustaquio Barjau, Madrid, Editora Nacional, 1977. Sobre todo el capítulo XVI que resume las diferencias entre la pintura y la poesía. 
ta algo (la tonalidad) o que ya han superado de manera decadente el "ideal" de la música. Además, tampoco la música étnica cabe en un sistema que se centra en la tonalidad, por lo que todo el "paradigma de la música clásica" es absurdo y no resuelve el problema de la definición de "música".

Aún más se complica el asunto si tomamos en consideración los "casos marginales" (aunque el empleo de este sintagma ya parte implícitamente de una idea central), como algunas obras de John Cage, por ejemplo su 4'33" (donde suena durante 4 minutos 33 segundos nada más que el silencio ante un piano o, según se mire, el ruido que producen los oyentes) o "Imaginary Landscape No. 4" (para 12 radios y 24 performers) del mismo autor. Y si vemos la Fuga geográfica de Ernst Toch ("Ratibor") o poemas como la Visio smaragdina de Juan Eduardo Cirlot ("Maresmer / maresmel vad / valma resdar / mares delmer [...]") con una sustancia musical innegable, tenemos serias dudas si todo ello aún es o no es música.

Pero quizá no deberíamos preguntar por la música, en el sentido de dar una definición rigurosa, sino, como ha pedido el filósofo americano Nelson Goodman respecto al arte, preguntar "cuándo hay arte", o, en nuestro contexto, "cuándo hay música". Lo importante no es el objeto estético, sino nuestra relación con él o la importancia que le otorgamos.

Tal como comentábamos al comienzo, parte de los problemas nacen de plantear una pregunta equivocada, de no aceptar que una cosa puede funcionar como obra de arte en algunos momentos y no en otros. En los casos más cruciales, la pregunta pertinente no es «zqué objetos son (permanentemente) obras de arte?» sino « ¿cuándo hay una obra de arte?» o, por decirlo más en breve, y con el título del capítulo, «¿cuándo hay arte?». Propondría contestar que de igual forma que un objeto puede considerarse un símbolo en un momento y circunstancias determinados y no en otros, como sucede, por ejemplo con una muestra, así también un objeto puede ser una obra de arte en algunos momentos y no en otros. De hecho, un objeto se convierte en obra de arte sólo cuando funciona como un símbolo de una manera determinada. La piedra no es normalmente una obra de arte cuando yace en la carretera, pero pudiera serlo en una exposición que se realiza en un museo ${ }^{12}$.

La situación condiciona el arte o dice qué es arte; un cuadro de Rembrandt, según Goodman, deja de ser arte "cuando se emplea para sustituir a una ventana rota o cuando se usa como una manta"13 $Y$, podríamos añadir, la $5^{\text {a }}$ sinfonía deja de ser una "obra de arte" cuando se usa como música de fondo en el supermercado. Pero, al revés, la función simbólica actúa también: si escucha-

12. Goodman, Nelson, Maneras de hacer mundos. Madrid, Visor, 1990, p. 98.

13. Ídem, p. 98. 
mos en un concierto de piano la composición $4^{\prime} 33^{\prime \prime}$ de John Cage, entonces hay que considerarla como arte. Es decir, los objetos de arte no son símbolos por sí mismos sino dependen del momento de su uso por nosotros. "Las cosas operan como obras de arte solo cuando su funcionamiento simbólico tiene determinadas características"14. Y estas características las Ilama Goodman "síntomas de lo estético", que son para él cinco: (1) la densidad sintáctica, (2) la densidad semántica, (3) la plenitud relativa, (4) la ejemplificación y (5) la referencia múltiple y compleja. Obviamente, no todos estos elementos tienen que encontrarse en el arte; aunque solo tuviéramos un elemento, entonces el símbolo se caracterizaría como arte (la poesía es sintácticamente más pobre que un artículo en un periódico; sin embargo, al último no lo llamaríamos arte).

Si aplicáramos estas ideas a una sinfonía, por ejemplo, la $5^{\underline{a}}$ sinfonía de Beethoven, no tendríamos ningún problema: la estructura musical es sintácticamente densa y no toleraría ni la más mínima diferencia (en una melodía de timbre el cambio de una nota no tendría ninguna consecuencia); además, los motivos empleados, similares al grosor en un cuadro, no tolerarían ninguna otra instrumentación (a la música del timbre eso le daría igual); la combinación de los elementos, su plenitud relativa como dice Goodman, exige una lectura de todos los signos en esta, y solo esta combinación, de las armonías o acordes, modulaciones, etc. (En el timbre los diferentes elementos pueden distribuirse de modo arbitrario). La ejemplificación (que es para Goodman una autorreferencia, como el muestrario de un tapicero) remite esta sinfonía a sí misma, es decir, solo consigue su sentido y su lógica en esta forma individual (y solo en esta). La referencialidad finalmente significaría que esta sinfonía la oímos siempre "en relación a" otras sinfonías (por ejemplo a las de Schubert) u otras interpretaciones. Una melodía del móvil o del timbre, al contrario, no tiene esta referencialidad, pues nos da igual si suena como otra melodía.

El truco, para llamarlo así, en la argumentación de Goodman es (o también el problema, según se mire) que una vez determinada la función simbólica del objeto como arte, después entran en vigor los síntomas de lo estético, pese a que ya antes estos objetos ya los poseían (una piedra en la calle o expuesta en el MoMA tienen la misma plenitud relativa). Además, el acercamiento de Goodman pretende de manera general elaborar una teoría simbólica del arte, pero no nos permite distinguir entre las diferentes artes. Si una obra de Earl Brown (por ejemplo Folio and Four Systems, 1952/53) es considerada una partitura (para la realización musical) o un cuadro (para ser colgado en la pared), no depende de los síntomas de lo estético; más bien simplemente del uso que hacemos de ello.

La dificultad de definir lo que es la música se mantiene, incluso aumenta, con la new musicology que entra en el discurso a partir de los años 80 del siglo XX.

14. Ídem, p. 99. 
Por una parte encontramos una vista mucho más crítica respecto a la idea de las "obras de arte", pues la categoría de la "obra" (que en cierto modo observamos implícitamente en la argumentación de Goodman) ya no es de interés primordial para los investigadores; ahora prima la práctica musical o la cultura musical en la que se desarrolla la música. La música había sido considerada hasta entonces, como hemos visto, una "obra estética y autónoma" y también un producto de la musicología académica, donde la exegesis del canon de las obras de los grandes maestros (sobre todo del repertorio clásico-romántico) sirvió en última consecuencia, así la crítica de la nueva musicología, como autoafirmación de la pequeña burguesía para insistir en un eurocentrismo y para fundamentar un patriarcado musical. Los métodos de la nueva musicología, por tanto, ya no se basaban ni en un positivismo de datos, fechas y obras, ni en la filología musical de las fuentes ${ }^{15}$; más bien se prima el pluralismo de los métodos, las múltiples perspectivas a la hora de acercarse al objeto de estudio, todo ello incluso en un lenguaje que a menudo no podría considerarse "académico". Las fronteras entre los tres pilares de la musicología tradicional (la musicología histórica, sistemática y comparativa) se fusionan ahora: la música es una práctica musical y un siempre objeto ideológico.

Sin embargo, este nuevo acercamiento a la música, en un primer momento más fresco que la "antigua" musicología, más espontáneo y liberado de cualquier coacción, que se expresa en textos y artículos como re-consideración, reescribir o re-pensar ${ }^{16}$, produce también y lógicamente su (propia) crítica, una crítica que se basa en el hecho de que hay que hablar (o escribir) de alguna manera sobre la música, es decir, hay que expresarse y comunicarse en un sistema diferente al de la música, lo que conlleva siempre sus dificultades. Y este recurso al lenguaje oral o escrito significa siempre y necesariamente el empleo de metáforas o comparaciones. Precisamente este es uno de los puntos débiles que observamos en un autor como Lawrence Kramer ${ }^{17}$, otro representante de la new musicology, que parte de la premisa de que la música y la literatura tienen la misma estructura para producir "significación"; la recepción, por tanto, es en ambos casos muy similar ${ }^{18}$. Pero esto no es nada nuevo, porque parte del

15. Precisamente eso lo criticaba Joseph Kerman en su libro Contemplating music: chaIlanges to musicology. Cambridge, Harvard University Press, 1985.

16. Cook, N. y Everist, Mark, Rethinking music. Oxford, OUP, 1999.

17. Kramer, Lawrence, Music as cultural practice. 1800-1900, Berkeley, University of California Press, 1993. Sobre todo el primer capítulo "Tropes and Windows: An Outline of Musical Hermeneutics".

18. Más críticas a la new musicology pueden encontrarse en el siguiente artículo: Bertone, Sophie, Wolfgang Fuhrmann, M. J. Grant, "Was ist neu an New Musicology?", en: Rebekka Habermas y Rebekka v. Mallinckrodt (ed.): Interkultureller Transfer und nationaler Eigensinn. Europäische und anglo-amerikanische Positionen der Kulturwissenschaften, Göttingen, Wallstein, 2004, pp.105-122. Véase sobre todo el capítulo "Zur Kritik an der New Musicology". 
antiguo topos de la música como lenguaje. De todas maneras, en las tendencias de los últimos 30 años se observa que la musicología está ampliando sus métodos, sus campos de investigación, y, como consecuencia, su concepto de lo que es la música.

Por tanto, en los siguientes textos encontraremos, más que soluciones a la pregunta "qué es la música", nuevas preguntas, ideas, juicios, perspectivas y acercamientos respecto a cómo se puede o se debe hablar sobre la música, cuáles son sus preocupaciones y sus retos, e incluso hasta qué punto aún tiene sentido hablar sobre la música. En la música como imagen Begoña Arrué nos revela, en el caso concreto de San Millán de la Cogolla, el importante papel que jugaban las canciones e instrumentos en la vida cotidiana del monasterio, un hecho que se refleja en los abundantes grafitos. Parece que el ser humano siempre haya subrayado el valor de la música mediante la iconografía. Carolina Queipo escribe sobre la música insonora; con este oxímoron analiza los beneficios y la utilidad del descubrimiento de un archivo musical, en este caso del fondo de partituras Adalid. Por una parte, un archivo obviamente conserva la partitura como una simple fijación de las relaciones entre las notas, pero revela también, por otra parte, su uso, o como es el caso del archivo Adalid su nouso, en un determinado contexto social; este corpus musicae funcionaba, como dice la autora del texto, también como importante referente simbólico externo del estatus social de la familia. Por tanto, esta "práctica musical" convierte la insonoridad de un archivo mudo en un lenguaje sonoro, vivo y actual. Miguel Ángel Marín realiza un estudio sobre la gestión musical; pese a que T. W. Adorno consideraba de manera peyorativa una gran parte de la música como mercancía, tenemos que reconocer que hoy en día la gestión es uno de los factores esenciales para que sea o exista la propia música. En una sociedad tan estructurada y organizada en todos los sentidos, la gestión musical es precisamente uno de los factores que garantiza a la música su supervivencia, sobre todo si se trata de estilos marginados y/o "raros".

El texto que nos ofrece Pablo-L. Rodríguez es una reflexión sobre un hecho de suma actualidad, pues contempla la música como resultado de las ideas de un productor musical o un ingeniero de sonido. Es decir, podría ser que la música, que en gran parte del siglo XX se conserva en y mediante grabaciones, nunca se escuche de forma pura sino siempre como "otro texto" intencionado por el productor musical. El trabajo de Esther López señala la estrecha relación entre la música y la literatura. Siempre en la historia de la música esta relación evoca una intertextualidad dudosa, que podría caracterizarse como coartada. Obviamente un texto sirve a menudo como punto de partida para la composición, pero las estructuras musicales que se emplean en formas literarias (sobre todo a partir del romanticismo) tienen poco que ver con la música misma; más bien son evocaciones que pretenden fusionar la música con la literatura.

Aunque la musicoterapia no aclare en última instancia "qué es la música", sin embargo el trabajo del musicoterapeuta Patxi López del Campo muestra que 
su parte expresivo-emotiva afecta indudablemente a todos los seres humanos. Su aplicación como medio terapéutico apunta hacia una idea que desde el siglo XVIII ha sido muy común: la música es un lenguaje universal que todo el mundo entiende y que repercute en el estado anímico de las personas. La importancia de la música en y para la educación, tal y como la describe Susana Flores en su aportación, muestra que algo de este fenómeno sonoro influye indudablemente en el desarrollo del ser humano. Pues para la enseñanza musical -pese a los rápidos cambios de las últimas décadas, tanto en los métodos como en los contenidos, donde la interculturalidad y las tecnologías de la Información y la Comunicación (TIC) juegan un papel importante- aún se mantiene como ideal la paideia, aquella armonía o equilibrio mental y corporal que ya fue fundamental para los antiguos griegos. Teresa Cascudo escoge el ejemplo de Manuel de Falla para entender la idea de la evocación, una categoría central tanto en su obra musical como en sus textos (teórico-musicales). Esta evocación musical parte siempre de una imagen que sirve de estímulo al compositor para musicalizar esta impresión. La música se revela, por tanto, no a través de un contenido musical concreto, en forma de descripción, sino de la impresión personal del compositor, de su intuición o, en última instancia, de su estado psíquico.

El texto de Jordi Raventós desde la perspectiva de la etnomusicología nos plantea la pregunta de si el estudio de la historia de la música no debería ser más una historia cultural (con una mirada más variopinta) que solo musicología histórica, es decir, comprender la música no como algo aislado (que se reduce a la sola partitura) sino como algo vivo que se realiza siempre en un contexto socio-cultural concreto. Aún así muestra este entendimiento desde la multidisciplinaridad diferentes perspectivas: desde un modo analítico-sistemático, lógico-científico, hasta un punto de vista histórico, antropológico-interpretativo. El acercamiento que nos hace Pilar Ramos desde el feminismo parte de la idea de que la música no debe ser considerada solo y exclusivamente como "historia de las obras musicales"; mas bien debería ser concebida y entendida adecuadamente bajo el aspecto de la historia cultural tomando en cuenta los diferentes papeles y roles de los hombres y mujeres que a lo largo de la historia de la música han existido. En este sentido, la música (hasta fechas recientes exclusivamente bajo dominio del hombre) hay que considerarla también como producto cultural donde las mujeres han jugado un rol importante y esencial sin que éste se haya apreciado y reconocido siempre adecuadamente.

Considerar la música como escucha, tal y como la enfoca el texto de Antonio Notario, es decir, como una nueva actitud activo-participativa ante el fenómeno sonoro, es una idea que surge precisamente de la crisis a finales del siglo XIX donde la tonalidad como "medio de arte" fue cuestionada por muchos compositores al considerarla insuficiente. Las consecuencias de esta crítica se ven en un giro sonoro que aboga por la corporalidad, la gestualidad, o, en general, una nueva escucha, todas ellas categorías que después el posmodernismo reclama para sí. La música como algo inteligible, como algo cuyo sentido le 
otorgamos nosotros (aunque parezca como si este sentido ya estuviera contenido en la música), es la idea que nos ofrece Edson Zamprona. Debido a que siempre somos capaces de entender la música, parece que se trate de una retroalimentación en el sentido de que la interpretación de la música, que supone un momento de entendimiento, ya se la hemos dado a la música. Pensar la música como (un) juego, como hace Thomas Schmitt, no es tan descabellado como parece a primera vista. Gracias a las semejanzas formales y estructurales existen en la historia varios intentos de reducir la composición a la mera combinación de notas sin que se cuestione su pretensión artística. El juego musical abre de esta manera un nuevo entendimiento incluso para la Ilamada música "clásica". El texto de Daniel Martín sobre la música y la locura esboza la idea de la inspiración a lo largo de la historia, cuya forma extrema es la locura. Pese a sus diferentes manifestaciones en función de las ideologías dominantes, parece que sin la locura una creación humano-artística no hubiera sido posible, ni en el arte en general ni en la música. Finalizamos el volumen con una reflexión de Luis Ángel de Benito en forma de siete tópicos que versan sobre algunos de los prejuicios que aún siguen en vigor a la hora de hablar sobre la música. La deconstrucción de conceptos como "música contemporánea" o la idea del "desentendimiento" de la música vanguardista nos hacen ver que en última instancia la cuestión radica en el tipo de música en concreto de que se trate.

Como se ve o se verá, este monográfico aboga por la pluralidad de opiniones sobre la "música". Por tanto, los textos pretenden enfocar, cada uno a su manera, algunos con más rigor científico, otros con menos, el vasto campo terminológico y conceptual de lo que es la música, de lo que podría ser la música, o, como decía Goodman, esbozar por lo menos las circunstancias para cuando sea posible este arte. Quizá todo esto haya sido en vano -eso tiene que decidirlo el lector-, pero por lo menos le hemos dedicado tiempo, esfuerzo y algo de reflexión, que siempre se lo merece.

Lo único que puede decirse con certeza sobre la música es, parafraseando una sentencia de San Agustín, “¿Qué es, pues, la música? Si nadie me lo pregunta, lo sé; pero si quiero explicárselo al que me lo pregunta, no lo sé."

No quiero terminar esta introducción sin expresar mi agradecimiento a José María Aguirre Oraá sin cuyo estímulo y ánimo este monográfico no hubiera sido posible. 